\title{
Mechanical and Geometrical Properties of Density-Separated Neonatal and Adult Erythrocytes
}

\author{
OTWIN LINDERKAMP, EDGAR FRIEDERICHS, AND HIERBERT J. MEISELMAN
}

Division of Ne'onatology: Departme'nt of Pediatrics. L'niversity of Heidelherg. D)-69120) Heidellherg. (ierman!

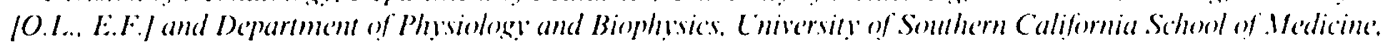

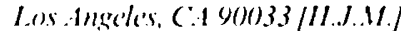

\begin{abstract}
ABSTRACI. Neonatal red blood cells (RBC) show large variations in size, density, and deformability, with a relatively high percentage of neonatal $\mathrm{RBC}$ being extremely dense, almost spherical, and poorly deformable. Previous reports suggest that loss of membrane and oxidation of fetal Hb might account for the generation of the dense, rigid $\mathrm{RBC}$ in neonates and the shortened life-span of neonatal RBC. To test whether the dense RBC population is particularly fragile and which mechanical properties are responsible for the rigidity of these cells, the following measurements were made for the top (least dense) and bottom (most dense) 3\% fractions of density-separated neonatal and adult RBC: cellular deformability (rheoscope); RBC geometry (micropipette system); elasticity, fragility, and viscosity of $\mathrm{RBC}$ membrane (micropipette system); IIb solution viscosity (cone-plate viscometer); and selected biochemical parameters. Fetal $\mathrm{H} / \mathrm{b}$ of neonatal $R B C$ decreased with increasing cell density. When the bottom fractions were compared with the top fractions, neonatal $\mathrm{RBC}$ showed a greater reduction in glutamic oxalacetic transaminase activity $(72 \%$ versus $53 \%)$, potassium (39\% versus $19 \%)$, volume (32\% versus $19 \%)$, and surface area $(42 \%$ versus $21 \%)$, and a greater rise in density (3.5\% versus $1.9 \%)$ and mean corpuscular Ilb concentration (42\% versus $23 \%$ ) than adult RBC. Cellular deformability in the rheoscope (shear stress 5 Pa) decreased by $24 \%$ in adults and by $41 \%$ in neonates. Membrane extensional and bending elastic moduli (i.e. membrane deformability) and membrane fragility of neonatal and adult RBC did not significantly change with increasing cell density. However, the membrane surface viscosity increased by $175 \%$ in the neonatal $\mathrm{RBC}$ and by $76 \%$ in the adult $\mathrm{RBC}$ when the bottom fractions were compared with the top fractions. Itb solution viscosity increased by $256 \%$ in neonatal and by $110 \%$ in adult RBC. But at a given $\mathrm{llb}$ concentration, Hb solution viscosity was similar in neonates and adults. The results indicate that the densest neonatal $\mathrm{RBC}$ are not particularly fragile and that the poor deformability of these cells results from loss of membrane surface area and rise of membrane and $\mathrm{Hb}$ viscosity. (Pediatr Res 34: 688-693, 1993)
\end{abstract}

\section{Abbreviations}

GOT, glutamic oxalacetic transaminase IIbF, fetal Hb

Received August 24. 1992; accepted April 6. 1993.

Correspondence: Dr. O Linderkinup, Universitits-Kinderklinik Hcidelberg. $1 \mathrm{~m}$ Veuenheimer Feld 150, D-69120 Heidelherg. Germany.

Supported by a research grant ( $\mathrm{Li} 291 / 4-3)$ from the Deutsche Forschungsgemeinschaft and by the National Institutes of Health (Grants HI.15922 and IIL41341).
MCIC, mean corpuscular IIb concentration NICV, mean corpuscular volume

RBC, red blood cell

Separation of normal human RBC according to their density results in the isolation of distinct $\mathrm{RBC}$ subpopulations. Increase in density is associated with loss of water, volume, and surface area, decrease in several enzyme activities, and increase in MCHC (1, 2). RBC deformability in adults decreases progressively with increasing cell density, due to decreasing surface area (i.e. increasing sphericity) and increasing membrane and thb viscosity (3-6).

Neonatal RBC show a markedly broader density distribution with a higher proportion of very light and extremely dense cells compared with adult RBC (7-9). Gahr ('t al. (7) observed that $15 \%$ of neonatal $\mathrm{RBC}$ have a density of $1.11 \mathrm{~g} / \mathrm{mL}$ or more, whereas only $5 \%$ of adult $\mathrm{RBC}$ show such a high density. The densest neonatal RBC show a greater increase in MCHC and a more pronounced decrease in enzyme activities, volume, surface area, and deformability than the densest adult $\mathrm{RBC}(1,8-10) . \mathrm{A}$ recent paper suggests that increased oxidation of $\mathrm{HbF}$ may contribute to the creation of the subpopulation of extremely dense RBC in neonates (11).

Dense RBC bind more $\operatorname{IgG}(9)$ and are quickly removed (12). This led to the assumption that RBC become more dense as they age and that density separation techniques can be used to obtain $\mathrm{RBC}$ of different ages (2). However, recent studies on in vivo aged $R B C$ suggest that the densest $R B C$ are not much older than unfractionated $R B C$ and that dense $R B C$ are formed at an earlier stage (13). Because dense RBC are quickly removed (12), increased generation of dense RBC may explain why the life-span of neonatal $R B C$ ranges from 45 to $70 \mathrm{~d}(14)$, whereas in adults most RBC show a fairly constant survival time of $120 \mathrm{~d}(2)$.

In the present investigation. we have studied several mechanical properties, surface area, volume, and deformability of density-separated neonatal and adult RBC to assess the following questions: I) Do the dense neonatal $\mathrm{RBC}$ represent a cell population with increased mechanical fragility of the membrane [similar to congenital spherocytosis (15)]? 2) Which of the determinants of RBC deformability (excess surface area, shape, membrane elasticity, membrane and internal viscosity) are responsible for the marked decline in the deformability of the dense neonatal RBC subpopulation? 3) Does the high HibF content of dense fetal RBC (7) contribute to the decrease in cellular deformability?

\section{MATERIALS AND METHODS}

Blood samples and RBC preparation. Placental blood samples from 15 healthy, vaginally born newborn infants with gestational 
ages of 39 to $40 \mathrm{wk}$ and birth weights of 3250 to $3630 \mathrm{~g}$ were studied with the approval of the Department of Pediatrics Human Subjects Research Committee. The umbilical artery $\mathrm{pH}$ was above 7.25, the 1-min Apgar score was 9 and the 2- and 5-min Apgar scores were 10 in all cases. Blood $(20 \mathrm{~mL})$ was collected from the placenta into EDTA (approximately $1 \mathrm{mg} / \mathrm{mL}$ ) immediately after cord clamping before delivery of the placenta. Adult blood samples $(20 \mathrm{~mL})$ were collected from 15 healthy male laboratory personnel (aged 21 to $35 \mathrm{y}$, nonsmokers, not obese) by venipuncture into EDTA. Ten neonatal and ten adult blood samples were collected for the micropipette studies; five neonatal and five adult blood samples were used for the measurements of $\mathrm{RBC}$ density and $\mathrm{Hb}$ solution viscosity. Blood samples were stored on ice during the transport to the laboratory and analyzed within $4 \mathrm{~h}$ after collection.

Part of each neonatal and adult blood sample was used for density separation as described in previous reports $(4,10)$. Whole blood was placed into $4-\mathrm{mm}$ internal diameter by $47-\mathrm{mm}$ long plastic tubes and centrifuged for $15 \mathrm{~min}$ at $12000 \times \mathrm{g}$. After centrifugation, the length of the red cell column was accurately measured and each tube was then cut at the border between the buffy coat and the RBC; the top $3 \%$ of the cells was then carefully removed. The tube was cut again very close to the lower end and the bottom $3 \%$ of the cells was removed. Top and bottom fractions thus contained $3 \%$ of the least and most dense cells, respectively. This method for $\mathrm{RBC}$ density separation does not use gradient media and thus does not separate RBC fractions with defined absolute densities. However, an important advantage of this method is that small quantities of top and bottom fractions are rapidly available: Neonatal $R B C$ have a tendency to assume an echinocytic shape if not studied promptly (16), and the rheologic and mechanical properties of $\mathrm{RBC}$ are very sensitive to shape changes (17).

Micropipetle sistem. Details of the microscope-video system. the micropipette system, the production and handling of micropipettes $(18,19)$, and the RBC preparation $(4,20)$ have been described previously. $\mathrm{RBC}$ were diluted at a hematocrit of about $0.001 \mathrm{~L} / \mathrm{L}$ in PBS containing $1 \mathrm{~g} / \mathrm{L}$ human serum albumin. Note that one neonatal and one adult blood sample were studied on the same day, using the same micropipette; $30 \mathrm{RBC}$ were tested in each sample for each micropipette method described below. Less than $5 \%$ of $\mathrm{RBC}$ in each sample showed microscopically visible echinocytic alterations. Echinocytes were excluded from the study because their mechanical properties may be altered (17).

RBC membrane elastic moduli, fragility, and viscosity: Pipettes with internal diameters of 1.4 to $1.6 \mu \mathrm{m}$ were used for studies of $\mathrm{RBC}$ recovery time from extensional deformation (21), membrane extensional and bending elastic moduli (6), and mechanical membrane fragility (19); each of these four measurements were carried out on the same RBC $(19,20)$.

The time constant for extensional shape recovery was studied by the method of Hochmuth ${ }^{\prime} t a l$. (21) and calculated as described by Nash and Meiselman (5). The pipette was used to extend (overall extension ratio of approximately 1.6) and quickly release point-attached RBC. From video recordings of the recovery process, the cell length-width ratio was measured every [1/ 50] $\mathrm{s}$ for 20 fields after releasing the cell. The extensional and bending elastic modulus and the mechanical fragility were then studied after the extended cell had recovered its initial shape (19. 20). A small membrane tongue was aspirated into the pipette from a flat portion of the cell surface $(6,22)$. Tongue length $\left(L_{T}\right)$ was measured from video recordings at a series of increasing aspiration pressures (P). Initially, a smooth membrane tongue forms in the pipette. Then the membrane begins to fold and finally the membrane ruptures. These sequential events were videorecorded and used to determine the extensional elastic modulus, the bending elastic modulus, the yield strain, and the yield tensile stress of the RBC membrane. The extensional (shear) elastic modulus $\left(\mu_{\mathrm{c}}\right)$ was calculated from a lincar relationship that exists between $L_{T} / R_{n}\left(R_{p}=\right.$ pipette radius $)$ and $P \cdot R_{n}$ over a $\mathrm{L}_{\mathrm{T}} / \mathrm{R}_{\mathrm{p}}$ range approximately between 1.5 and $3(6)$ :

$$
\mathrm{L}_{\mathrm{T}} / \mathrm{R}_{\mathrm{p}} \propto\left(1 / \mu_{\mathrm{c}}\right) \cdot \mathrm{P} \cdot \mathrm{R}_{\mathrm{p}}
$$

For a given pipette radius, $\mu_{\mathrm{c}}$ defines the pressure required to produce a defined membrane tongue length. In other words, $\mu_{\mathrm{e}}$ determines $\mathrm{RBC}$ membrane deformation in response to a given force. A small $\mu_{\mathrm{e}}$ indicates little resistance to deformation and high membrane flexibility. The membrane viscosity was calculated as product of the time constant for extensional shape recovery and the extensional elastic modulus (6). Membrane bending elastic modulus (i.e. resistance to membrane bending and folding) was derived from the pressure at which the membrane began to fold during aspiration of the membrane tongue into the micropipette $(6,20)$.

The strain $(\phi)$ in the cylindrical section of the aspirated membrane tongue is $(19,22)$ :

$$
\begin{aligned}
\phi & =(1 / 4)\left[\left(A_{p} / R_{p}{ }^{2}\right)+\ln \left(1+A_{p} / R_{p}{ }^{2}\right)\right] \\
A_{p} & =\left(A_{\text {cap }}+A_{c y 1}-\pi R_{p}{ }^{2}\right) / \pi
\end{aligned}
$$

where $A_{\text {can }}$ is the surface area of the cap of the aspirated membrane tongue and $A_{c y l}$ is the surface area of the cylinder portion. The strain $\phi$ in the membrane reflects the extent of membrane deformation (i.e. the membrane tongue length in the pipette). The yield strain of the membrane defines the maximum deformation that the membrane can reach before it yields and ruptures, $\phi \times \mu_{\mathrm{c}}$ is the tensile stress. Tensile strength at the yield point of the membrane is the yield tensile stress.

$R B C$ geometry: Pipettes with internal diameters of 1.8 to 2.0 $\mu \mathrm{m}$ were used for the determination of RBC surface area and volume (23); the resting diameters of $R B C$ were measured before micropipette aspiration. Other RBC geometrical characteristics, i.c. mean thickness, surface area index, swelling index, and minimum cylindrical diameter, were calculated based upon cell diameter, surface area, and volume. Note that both the surface area index and the swelling index have a limiting value of 1.0 for a spherical shape. A surface area of 1.40 indicates an excess surface area beyond that required to enclose the cellular volume of $40 \%$. A swelling index of 1.65 indicates that the volume of a $\mathrm{RBC}$ can swell by $65^{\circ}$ (swelling capacity) before it reaches spherical shape and hemolyzes. The minimum cylindrical diameter is the width of an RBC with cylindrical shape and defines the narrowest cylindrical tube through which an $\mathrm{RBC}$ can pass.

IIb solution viscosity. Hb solutions were prepared from unfractionated $R B C$ and from top and bottom fractions of five neonatal and five adult blood samples according to the method described by Cokelet and Meiselman (24). The Hb concentrations of the solutions from top and bottom RBC were adjusted to the mean intracellular $\mathrm{Hb}$ concentrations determined in the first part of the study for the corresponding cell types (Table 1). The concentrations of $\mathrm{Hb}$ solutions from unfractionated neonatal and adult $\mathrm{RBC}$ were also adjusted at the mean values determined in the first study for unfractionated, top, and bottom cells. $\mathrm{Hb}$ solution viscosities were measured at $37^{\circ} \mathrm{C}$ using a WellsBrookfield cone-plate viscometer (Brookfield Engineering Labs., Stoughton, MA).

$R B C^{\prime}$ deformahility: Deformability of single $\mathrm{RBC}$ was assessed using a counter-rotating, cone-plate rheoscope (25) (Effenberger, Munich, Germany) that was mounted on an inverted microscope (Leitz Diavert, Wetzlar, Germany). Details of the method have been described elsewhere (26). For the deformability measurements. RBC were diluted at a hematocrit of about $0.01 \mathrm{~L} / \mathrm{L}$ in PBS containing $200 \mathrm{~g} / \mathrm{L}$ dextran T-70 (Pharmacia, Uppsala, Sweden). The osmolality of these dextran solutions was $295 \pm 5$ mosmol $/ \mathrm{kg}$ and the viscosity was $21 \mathrm{mPa} \cdot \mathrm{s}$ at $25^{\circ} \mathrm{C}$. Shear stresses of $0.5,5$, and $50 \mathrm{~Pa}$ were applied, and the elongation of single RBC was evaluated on photomicrographs. Length (L) and width (W) of $40 \mathrm{RBC}$ were measured in each sample at each 
Table 1. General propertices of unfractionated, top, and hottom RBC*

\begin{tabular}{|c|c|c|c|c|}
\hline & & Top & Unfractionated & Bottom \\
\hline \multirow[t]{2}{*}{ Mean density $(\mathrm{g} / \mathrm{mL})$} & $\mathrm{N}$ & $1.079 \pm 0.005 \dagger \ddagger$ & $1.099 \pm 0.005 \ddagger$ & $1.119 \pm 0.006 \dagger$ \\
\hline & $A$ & $1.089 \pm 0.004 \ddagger$ & $1.101 \pm 0.003 \ddagger$ & $1.111 \pm 0.003$ \\
\hline \multirow[t]{2}{*}{$\operatorname{MCV}(\mathrm{n})$} & $\mathrm{N}$ & $129.7 \pm 12.3+\ddagger$ & $105.7 \pm 5.1+\ddagger$ & $88.1 \pm 4.7 \dagger$ \\
\hline & $A$ & $96.8 \pm 5.5 \ddagger$ & $89.5 \pm 3.9 \ddagger$ & $79.7 \pm 3.5$ \\
\hline \multirow[t]{2}{*}{$\mathrm{MCH}(\mathrm{fmol})$} & $\mathrm{N}$ & $2.19 \pm 0.15 \dagger$ & $2.17 \pm 0.11 \dagger$ & $2.14 \pm 0.21+$ \\
\hline & $A$ & $1.83 \pm 0.12$ & $1.85 \pm 0.09$ & $1.81 \pm 0.10$ \\
\hline \multirow[t]{2}{*}{$\mathrm{MCHC}(\mathrm{mmol} / \mathrm{L})$} & $\mathrm{N}$ & $16.9 \pm 1.6+\ddagger$ & $20.4 \pm 0.9 \ddagger$ & $24.0 \pm 1.4 \dagger$ \\
\hline & $A$ & $18.6 \pm 1.17$ & $20.6 \pm 0.8 \ddagger$ & $22.9 \pm 1.1$ \\
\hline \multirow{2}{*}{ GOT (IU/mmol Hb) } & $\mathrm{N}$ & $332 \pm 87 \dagger \ddagger$ & $137 \pm 47 \dagger \ddagger$ & $92 \pm 4(0 \dagger$ \\
\hline & A & $130 \pm 40 \ddagger$ & $76 \pm 24$ & $61 \pm 23$ \\
\hline \multirow[t]{2}{*}{$\mathrm{K}^{+}(\mathrm{mmol} / \mathrm{mmol} \mathrm{Hb})$} & $\mathrm{N}$ & $1905 \pm 264 \dagger$ & $1758 \pm 137 \ddagger \ddagger$ & $1171 \pm 9.3+$ \\
\hline & $A$ & $1676 \pm 121$ & $1575 \pm 95 \ddagger$ & $1357 \pm 103$ \\
\hline \multirow[t]{2}{*}{$\operatorname{HbF}\left(m_{0}\right)$} & $\mathrm{N}$ & $36.4 \pm 8.7 \dagger \ddagger$ & $65.7 \pm 7.8 \dagger$ & $73.6 \pm 9.5 \dagger$ \\
\hline & $A$ & $0.6 \pm 0.3$ & $0.7 \pm 0.3$ & $0.8 \pm 0.4$ \\
\hline \multirow[t]{2}{*}{ Reticulocytes $(\%)$} & $\mathrm{N}$ & $25.3 \pm 9.6+\ddagger$ & $5.0 \pm 1.8 \dagger \ddagger$ & $0.4 \pm 0.2$ \\
\hline & $\mathrm{A}$ & $10.9 \pm 2.7 \ddagger$ & $1.2 \pm 0.4 \ddagger$ & $0.2 \pm 0.1$ \\
\hline
\end{tabular}

* Data represent mean \pm 1 SD of the sample means. MCH, mean corpuscular Hb; A, adults; N, neonates. MCV was obtained via the Contraves system. Mean RBC density was determined in five neonatal and five adult blood samples, whereas the other parameters were studied in 10 neonatal and 10 adult blood samples.

$\dagger$ Neonatal and adult RBC (same fraction) significantly different: $p<0.05$ (unpaired test).

¥ Top or bottom RBC significantly different from unfractionated RBC: $p<0.05$ (paired-difference test).

shear stress, with $\mathrm{RBC}$ elongation $(\mathrm{E})$ expressed as $\mathrm{E}=(\mathrm{L}-\mathrm{W})$ / $(\mathrm{L}+\mathrm{W})$. E increases with increasing cellular deformation.

Miscellaneous techniques. RBC count, MCV, and Hb concentration were measured using a cell counter (Contraves, Zürich, Switzerland). Reticulocytes were counted after the staining of a blood smear by brilliant cresyl blue. HbF was quantified by the alkali denaturation test (27). GOT was measured with a test kit (Boehringer, Mannheim, Germany) (7). Intraerythrocytic potassium concentration was determined by flame photometry (28). Density distribution of fractionated and unfractionated $\mathrm{RBC}$ was studied by the phthalate-oil method (29) as reported elsewhere (13).

Statistical analyses. Arithmetic means were calculated for 30 (micropipette studies) or 40 (rheoscope) RBC tested in each sample of unfractionated, top, and bottom fractions. These sample means were used to calculate the means and SD for each parameter. One-way analysis of variance was used to test for overall differences between unfractionated, top, and bottom RBC fractions in neonates and adults. If the overall $F$ ratio was found to be significant $(p<0.05)$. Tukey's honestly significant-difference test (30) was used to analyze 1 ) the differences of corresponding $\mathrm{RBC}$ fractions between neonates and adult (unpaired comparisons), and 2) the differences among various RBC fractions separately for neonates and adults (paired comparisons).

\section{RESULTS}

Unfractionated $R B C$. The hematologic, geometric, and mechanical properties of unfractionated $R B C$ are shown in Tables 1-3. MCV obtained via Contraves cell counter (Table 1) and volume determined by means of micropipette system (Table 2) were not significantly different. MCV, mean corpuscular $\mathrm{Hb}$, $\mathrm{HbF}, \mathrm{GOT}$ activity, and potassium concentration of neonatal RBC were markedly higher than those of adult RBC (Table 1). Figure 1 shows that the density of neonatal $R B C$ ranged from 1.074 to $1.122 \mathrm{~g} / \mathrm{mL}$, whereas the density of adult $\mathrm{RBC}$ ranged from 1.082 to $1.118 \mathrm{~g} / \mathrm{mL}$. Compared with adult $\mathrm{RBC}$, the volume of neonatal $\mathrm{RBC}$ was $18 \%$ larger, their surface area was $12 \%$ greater, and their diameter was $11 \%$ wider (Table 2 ). The surface area to volume ratio of the neonatal $\mathrm{RBC}$ was significantly decreased and their minimum cylindrical diameter was increased compared with adult cells. There were no significant differences between neonatal and adult RBC for mean thickness, surface area index, and swelling index.

Cellular deformability as measured in the rheoscope did not show significant differences between the neonates and adults at any of the applied shear stresses (Table 3). Both the extensional and the bending elastic moduli of the neonatal RBC were $12 \%$ smaller, whereas the time constant for recovery from extensional deformation was $25 \%$ larger than that for adult cells. Membrane viscosity and the yield strain were similar in neonates and adults. The yield tensile stress was $21 \%$ lower in neonates than in adults.

Fractionated RBC. GOT activity decreased markedly from the top fraction to the unfractionated cells, whereas the potassium concentration decreased mainly from the unfractionated to the bottom cells (Table 1). HbF in the neonatal bottom RBC was two times higher than in the top fraction, but similar in the unfractionated and bottom $\mathrm{RBC}$.

When the bottom fractions were compared with the top fractions, neonatal $\mathrm{RBC}$ showed a greater rise in density $(3.5 \%$ versus. 1.9\%) and MCHC (42\% v'rsus $23 \%)$ than adult RBC (Table 1$)$. Moreover, neonatal RBC lost about twice as much surface area $(-42 \%$ versus $-21 \%)$ and volume $(-32 \%$ versus $-19 \%)$ as adult RBC (Table 2). The excess surface area decreased from $49 \pm 7 \%$ to $12 \pm 4 \%$ for the neonatal $\mathrm{RBC}$ and from $46 \pm 5 \%$ to $33 \pm$ $4 \%$ for adult $\mathrm{RBC}$ when the bottom fractions were compared with the top fractions (Table 2). The swelling capacity of RBC decreased from $82 \pm 8 \%$ to $19 \pm 5 \%$ in the neonates and from $75 \pm 6 \%$ to $53 \pm 5 \%$ in the adults. Thus, the dense neonatal $\mathrm{RBC}$ had much less excess surface area (12\% versus $33 \%)$ and swelling capacity ( $19 \%$ v'ersus 53\%) than the dense adult RBC.

For both neonatal and adult RBC, the membrane extensional and bending elastic moduli, the yield strain, and tensile stress did not significantly change with increasing cell density (Table 3). The time constant for recovery from extensional deformation of neonatal and adult RBC increased markedly with increasing density, with the increase being more pronounced for neonatal $\mathrm{RBC}$ than for adult cells $(+140 \%$ versus $+60 \%)$. Note that the most dense neonatal RBC needed $50 \%$ more time for recovery from extensional deformation than the most dense adult $\mathrm{RBC}$ (Table 3).

The calculated membrane viscosity was also increased more for the dense neonatal RBC than for the dense adult RBC compared with the corresponding least dense (top) cell fractions $(+175 \%$ versus $+76 \%)$. Figure 2 shows the Hb solution viscosities as functions of $\mathrm{MCHC}$; it is clear that a single curve describes the data for all adult and neonatal samples. Table 4 presents the viscosities of various $\mathrm{Hb}$ solutions, where at any given $\mathrm{Hb}$ concentration, the viscosity was similar for solutions prepared from nconatal and adult RBC or from fractionated and unfrac- 
Table 2. Geometric dala for unfiractionated, top, and bottom $R B C^{*}$

\begin{tabular}{|c|c|c|c|c|}
\hline & & Top & Unfractionated & Bottom \\
\hline \multirow[t]{2}{*}{ Volume (fL) } & $\mathrm{N}$ & $130.8 \pm 13.1+\ddagger$ & $107.3 \pm 5.6+\ddagger$ & $89.4 \pm 5.9 \dagger$ \\
\hline & $A$ & $99.2 \pm 6.3 \ddagger$ & $90.5 \pm 4.4 \ddagger$ & $80.3 \pm 4.0$ \\
\hline \multirow{2}{*}{ Surface area $\left(\mu \mathrm{m}^{2}\right)$} & $\mathrm{N}$ & $186.1 \pm 10.6+\ddagger$ & $153.5 \pm 7.0 \dagger \ddagger$ & $108.5 \pm 8.2 \dagger$ \\
\hline & $A$ & $150.6 \pm 8.4 \ddagger$ & $137.1 \pm 6.7 \ddagger$ & $118.6 \pm 6.2$ \\
\hline \multirow[t]{2}{*}{ Surface area/volume } & $\mathrm{N}$ & $1.43 \pm 0.05 \dagger$ & $1.43 \pm 0.04+\ddagger$ & $1.21 \pm 0.05 \dagger$ \\
\hline & $A$ & $1.51 \pm 0.03$ & $1.51 \pm 0.04$ & $1.49 \pm 0.04$ \\
\hline \multirow[t]{2}{*}{ Diameter $(\mu \mathrm{m})$} & $N$ & $9.8 \pm 0.4+\ddagger$ & $8.8 \pm 0.4 \ddagger$ & $6.9 \pm 0.5$ \\
\hline & $A$ & $8.6 \pm 0.5 \ddagger$ & $7.9 \pm 0.4$ & $7.5 \pm 0.4$ \\
\hline \multirow{2}{*}{ Mean thickness $(\mu \mathrm{ml})$} & $\mathrm{N}$ & $1.70 \pm 0.11$ & $1.76 \pm 0.10 \ddagger$ & $2.39 \pm 0.13 \dagger$ \\
\hline & $A$ & $1.71 \pm 0.11 \ddagger$ & $1.84 \pm 0.13$ & $1.83 \pm 0.14$ \\
\hline \multirow[t]{2}{*}{ Surface area index } & $N$ & $1.49 \pm 0.07 \ddagger$ & $1.40 \pm 0.05 \ddagger$ & $1.12 \pm 0.04 \dagger$ \\
\hline & $A$ & $1.46 \pm 0.05 \ddagger$ & $1.41 \pm 0.04 t$ & $1.33 \pm 0.04$ \\
\hline \multirow{2}{*}{ Swelling index } & $\mathrm{N}$ & $1.82 \pm 0.08 \div$ & $1.67 \pm 0.06 \ddagger$ & $1.19 \pm 0.05 \dagger$ \\
\hline & $\mathrm{A}$ & $1.75 \pm 0.06+$ & $1.66 \pm 0.04 \ddagger$ & $1.53 \pm 0.05$ \\
\hline \multirow{2}{*}{ Minimum cylindrical diameter $(\mu \mathrm{m})$} & $\mathrm{N}$ & $2.93 \pm 0.12$ & $3.00 \pm 0.14 t \ddagger$ & $3.83 \pm 0.32+$ \\
\hline & $A$ & $2.80 \pm 0.12$ & $2.83 \pm 0.14$ & $2.89 \pm 0.13$ \\
\hline
\end{tabular}

* Data represent mean \pm 1 SD of the sample means. A. adults: N. neonates. Volume and surface area were obtained via a micropipette system. Each parameter was studied in 10 neonatal and 10 adult blood samples.

+ Neonatal and adult RBC (same fraction) significantly different: $p<0.05$ (unpaired test).

$\ddagger$ Top or bottom RBC significantly different from unfractionated RBC: $p<0.05$ (paired-difference test).

Table 3. Mechanical properties of unseparated. $10 \mathrm{p}$, and bottom $R B C^{*}$

\begin{tabular}{|c|c|c|c|c|}
\hline & & Top & Unfractionated & Bottom \\
\hline \multirow{2}{*}{ Extensional elastic modulus $\left(\mu_{\mathrm{c}}: 10^{-6} \mathrm{~N} / \mathrm{m}\right)$} & $N$ & $5.2 \pm 0.6+$ & $5.4 \pm 0.7 \dagger$ & $5.8 \pm 0.7$ \\
\hline & $A$ & $5.9 \pm 0.5$ & $6.2 \pm 0.6$ & $6.5 \pm 0.8$ \\
\hline \multirow{2}{*}{ Time constant ( $\left.t_{e}\right)$ for extensional recovery $(\mathrm{s})$} & $\mathrm{N}$ & $0.10 \pm 0.02 \ddagger$ & $0.15 \pm 0.02 \dagger \ddagger$ & $0.24 \pm 0.03 \dagger$ \\
\hline & $A$ & $0.10 \pm 0.02 \ddagger$ & $0.12 \pm 0.02 \ddagger$ & $0.16 \pm 0.03$ \\
\hline \multirow{2}{*}{ Membrane viscosity $\left(\mu_{\mathrm{e}} \cdot \iota_{\mathrm{e}} ; 10^{-6} \mathrm{~N} \cdot \mathrm{s} / \mathrm{m}\right)$} & $\mathrm{N}$ & $0.53 \pm 0.10 \ddagger$ & $0.76 \pm 0.15 \ddagger$ & $1.46 \pm 0.24 \dagger$ \\
\hline & $A$ & $0.59 \pm 0.11 \ddagger$ & $0.78 \pm 0.13 \ddagger$ & $1.04 \pm 0.18$ \\
\hline \multirow{2}{*}{ Bending elastic modulus $\left(10^{-18} \mathrm{~N} \cdot \mathrm{m}\right)$} & $N$ & $14.3 \pm 2.6 \dagger$ & $15.5 \pm 2.7 \dagger$ & $16.0 \pm 2.3 \dagger$ \\
\hline & $\wedge$ & $16.2 \pm 2.5$ & $17.1 \pm 2.2$ & $17.9 \pm 3.4$ \\
\hline \multirow{2}{*}{ Yield strain } & $\mathrm{N}$ & $6.0 \pm 0.6$ & $6.4 \pm 0.9$ & $6.6 \pm 0.9$ \\
\hline & $A$ & $6.5 \pm 0.9$ & $6.7 \pm 1.0$ & $7.0 \pm 1.4$ \\
\hline \multirow[t]{2}{*}{ Yicld tensile stress $\left(10^{-h} \mathrm{~N} / \mathrm{m}\right)$} & $\mathrm{N}$ & $31.5 \pm 4.3 \dagger$ & $33.9 \pm 4.0 \dagger$ & $37.3 \pm 5.2 \dagger$ \\
\hline & $A$ & $39.8 \pm 5.7$ & $43.4 \pm 6.1$ & $45.6 \pm 6.8$ \\
\hline \multirow{2}{*}{$\mathrm{RBC}$ deformation at $5 \mathrm{~Pa}$ (rheoscope) } & $\mathrm{N}$ & $0.51 \pm 0.03+\ddagger$ & $0.41 \pm 0.03 \ddagger$ & $0.32 \pm 0.04 \dagger$ \\
\hline & $A$ & $0.47 \pm 0.0 .3 \ddagger$ & $0.42 \pm 0.03 \ddagger$ & $0.36 \pm 0.04$ \\
\hline
\end{tabular}

* Data represent mean \pm 1 SD of the sample means. A, adults: N, neonates. Each parameter was studied in 10 neonatal and 10 adult blood samples.

+ Neonatal and adult RBC (same fraction) significantly different: $p<0.05$ (unpaired test).

$\ddagger$ Top or bottom RBC significantly different from unfractionated RBC; $p<0.05$ (paired-difference test).

tionated RBC. However, for solutions prepared at Hb concentrations appropriate for the fractionated cells, significant differences were observed (adult top $31 \%$ greater than neonatal top, adult bottom 23\% less than neonatal bottom).

The most dense RBC showed significantly decreased deformability in the rheoscope compared with the least dense RBC (Table 3). The least dense neonatal RBC had significantly higher deformability than the least dense adult cells, whereas the most dense neonatal $R B C$ were less deformable than the most dense adult RBC. Figure 3 indicates that RBC deformation, at constant shear stress, decreased with increasing $\mathrm{MCHC}$ for both cell types.

\section{DISCUSSION}

In agreement with previous studies (7-9, 29), we observed a wider density range for neonatal RBC (Fig. 1). The greater increase in density of neonatal $\mathrm{RBC}$ from the top to the bottom fraction was associated with greater rise in $\mathrm{MCHC}$ and a more pronounced decrease in MCV and surface area (Table 2). Matovcik et al. (8) report smaller volumes and surface areas for the top fraction of neonatal $\mathrm{RBC}$, probably because their top fraction comprised $15 \%$ of the RBC, whereas we separated only $3 \%$ of the top cells.

The production of $\mathrm{HbF}$ decreases by $3 \%$ per week from 26 to
43 wk of gestation (31). This implies that the HbF content of the youngest neonatal RBC should be $30 \%$ lower than the $\mathrm{HbF}$ of the oldest cells, because the oldest RBC in full-term neonates are about $10 \mathrm{wks}$ old (14). This corresponds to our finding of a $37 \%$ difference in $\mathrm{HbF}$ between top and bottom $\mathrm{RBC}$ in neonates (Table 1). In particular, we found considerably less $\mathrm{HbF}$ in the top fraction of neonatal $\mathrm{RBC}$ compared with unfractionated cells (Table 1). This indicates that the least dense neonatal RBC are younger than the average unfractionated neonatal RBC. The average unfractionated $\mathrm{RBC}$ survives about $4 \mathrm{wk}$ in the circulation (14). Thus, HbF in the oldest neonatal RBC should be about $12 \%$ higher than in the unfractionated $\mathrm{RBC}$. The most dense neonatal RBC showed $8 \%$ more HbF than unfractionated neonatal RBC (Table 1). Because the difference was not statistically significant, we cannot conclude from this result that in neonates the most dense $R B C$ are older than unfractionated $R B C . A$ recent study on in vivo aged $R B C$ in children with transient erythroblastopenia indicated that the most dense $R B C$ are not much older than unfractionated RBC (13).

The exact mechanism for the loss of membrane surface area from dense cells is unknown. Four possible mechanisms may be discussed: 1) Membrane may be lost by endocytosis (8). 2) RBC membrane fragments may be removed by immunologic mechanisms (9). 3) HbF and other proteins in neonatal RBC are highly 


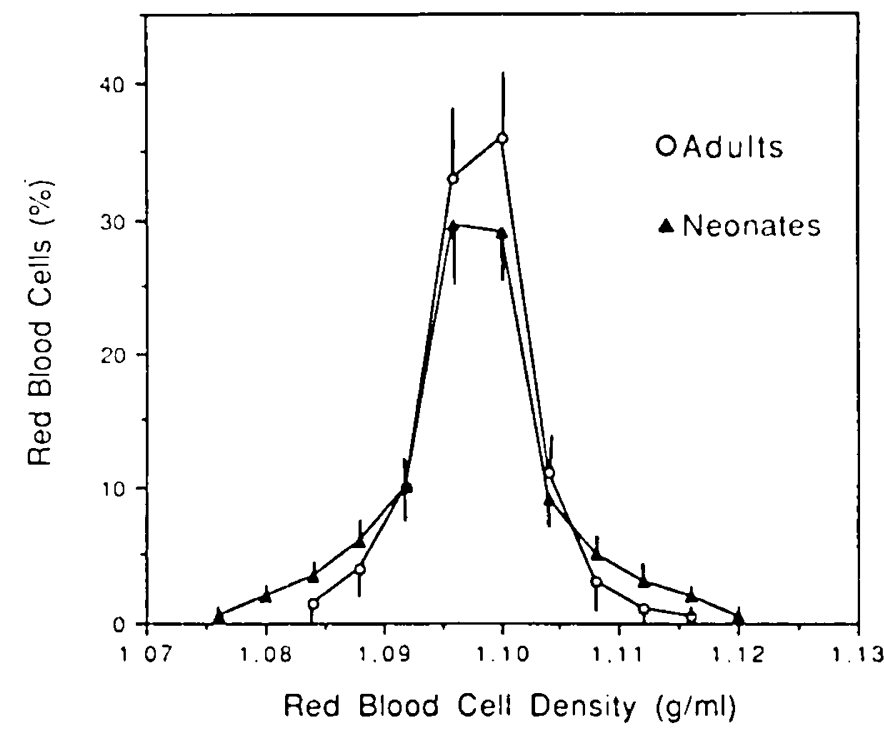

Fig. 1. Density distribution of unfractionated $R B C$ in full-term newborn infants $(\boldsymbol{\Delta})$ and adults $(\mathrm{O})$. Note that the distribution in neonates was broader than in adults.

susceptible to oxidative damage (11). 4) The continuous mechanical stress acting on the membrane of circulating RBC may result in fragmentation of the $\mathrm{RBC}$ membrane (15). Mechanical fragmentation of $\mathrm{RBC}$ membrane is principally a result of extreme elastic membrane deformation. RBC have to be extremely flexible to pass through narrow capillaries and splenic slits, whereas the RBC membrane must withstand the continuous strain resulting from frequent deformations. In general. extremely flexible (i.e. highly elastic) membranes are less resistant to mechanical fragmentation (e.g. spherocytosis) than membranes with normal elasticity (15).

The smaller elastic moduli and the reduced critical tensile stress for membrane fragmentation of neonatal RBC (Table 3) indicate that the membrane of neonatal $\mathrm{RBC}$ is more deformable and more fragile than the membrane of adult RBC. Compared with adult $\mathrm{RBC}$, the membrane of neonatal $\mathrm{RBC}$ ruptured at smaller pressure (i.e. smaller tensile stress) but at similar extent of membrane deformation (i.e. similar strain). A recent study on $\mathrm{RBC}$ membrane fragility using a flow channel showed that neonatal RBC lose more membrane per unit time (19). Thus, the membrane of neonatal $\mathrm{RBC}$ is more fragile due to increased membrane deformability and faster membrane loss. Because membrane elasticity and fragility did not significantly change with increasing cell density (Table 3 ), the dense neonatal RBC do not represent a cell population with increased mechanical fragility of the membrane. Moreover, our results suggest that increased binding of oxidized $\mathrm{Hb}$ to the membrane of the densest neonatal RBC (11) does not alter their membrane elasticity and fragility.

The biochemical basis for the different membrane mechanical properties of neonatal RBC is unknown. Neonatal and adult $\mathrm{RBC}$ show no qualitative or gross quantitative differences in the pattern of the membrane proteins (9), but neonatal RBC contain a greater proportion of unsaturated fatty acids (16), and membrane lipids of neonatal RBC are more susceptible to oxidative damage (32).

Because Hb solution viscosities in unfractionated and fractionated RBC were similar at given $\mathrm{Hb}$ concentrations (Table 4), we conclude that the increase in Hb viscosity in the densest $R B C$ was due solely to the elevated $\mathrm{Hb}$ concentration and not to altered Hb properties (e.g. oxidized Hb) (11). The increase in MCHC of dense $R B C$ is associated with an increase in membrane-bound $\mathrm{Hb}(9,11)$. Increased membrane-bound $\mathrm{Hb}$ results in increased membrane shear viscosity but does not alter membrane elasticity (33). Thus, the increased membrane viscosity in the most dense neonatal RBC (Table 3 ) is probably a result of increased membrane-associated $\mathrm{Hb}(9,11)$. It is unclear whether increased membrane-attached oxidized $\mathrm{Hb}$ in dense neonatal $\mathrm{RBC}$ (11) contributes to the high membrane viscosity.

RBC deformability depends on cell geometry (i.e. excess surface area and shape), membrane deformability (i.c. extensional and bending elastic modulus), and viscous properties (i.e. membrane and $\mathrm{Hb}$ viscosity) (17): 1) The excess surface area determines the maximum extent of whole cell deformation: 2) membrane elasticities determine the forces required for a given extent of membrane deformation; and 3) membrane viscosity limits the rate of membrane deformation. whereas the Hb viscosity determines the rate of cell bending and folding (6). Deformation of neonatal RBC decreased markedly more compared with adult

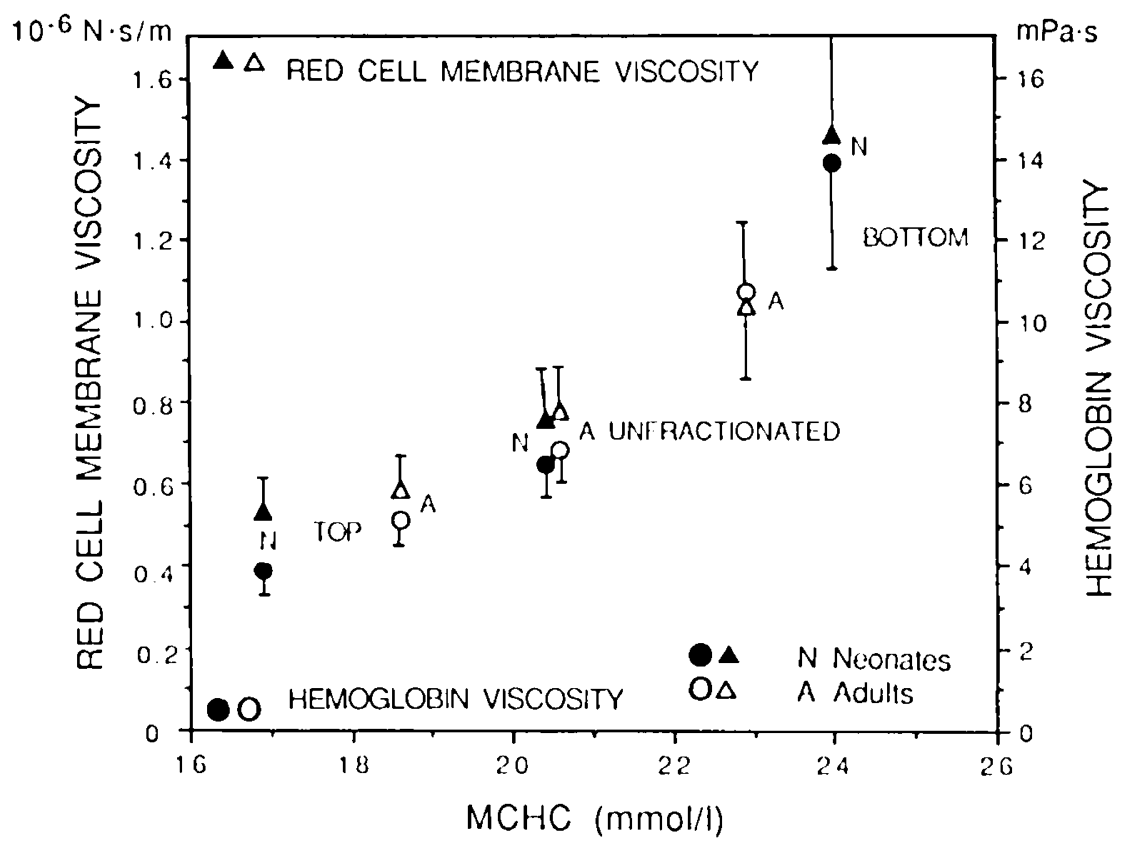

Fig. 2. Membranc viscosity (triangles) and Ifb viscosity (circles) of top (light), bottom (dense), and unfractionated neonatal (clesced simbols) and adult (open simbols) RBC plotted as a function of MCIIC. Data represent mean \pm 1 SD for 10 neonatal and 10 adult samples. 
Table 4. Viscosity of IHb solutions prepared from neonatal and achult $R B C^{*}$

\begin{tabular}{|c|c|c|c|}
\hline \multirow{3}{*}{$\begin{array}{l}\text { Ho concen- } \\
\text { tration } \\
(\mathrm{mmol} / \mathrm{L})\end{array}$} & \multicolumn{3}{|c|}{ Hb solution viscosity $(\mathrm{mPa} \cdot \mathrm{s})$} \\
\hline & \multicolumn{2}{|c|}{ Unfractionated red cells } & \multirow{2}{*}{$\begin{array}{c}\text { Top or bottom red } \\
\text { cells }\end{array}$} \\
\hline & $\mathrm{N}$ & $\wedge$ & \\
\hline 18.8 & $3.5 \pm 0.5$ & $3.7 \pm 0.4$ & $3.9 \pm 0.6(\mathrm{~N}, \mathrm{~T}) \dagger$ \\
\hline 18.6 & $4.6 \pm 0.7$ & $4.8 \pm 0.6$ & $5.1 \pm 0.7(\mathrm{~A} . \mathrm{T})$ \\
\hline 20.5 & $6.5 \pm 0.9$ & $6.8 \pm 0.8$ & \\
\hline 23.0 & $9.8 \pm 1.6$ & $10.3 \pm 2.1$ & $10.7 \pm 1.9(\mathrm{~A}, \mathrm{~B})$ \\
\hline 24.2 & $12.4 \pm 2.0$ & $13.0 \pm 2.9$ & $13.9 \pm 2.8($ N.B $) \dagger$ \\
\hline
\end{tabular}

* Values are mean $\pm 1 \mathrm{SD} ; \mathrm{A}$, adults; $\mathrm{N}$, neonates; $\mathrm{B}$, bottom red cells: T, top red cells. Hb concentrations were adjusted to the mean MCHC values found in the first part of the study (Table 1). The studies were performed in five neonatal and five adult blood samples.

$\uparrow$ Neonatal and adult RBC (same fraction) significantly different $p<$ 0.05 (unpaired test).

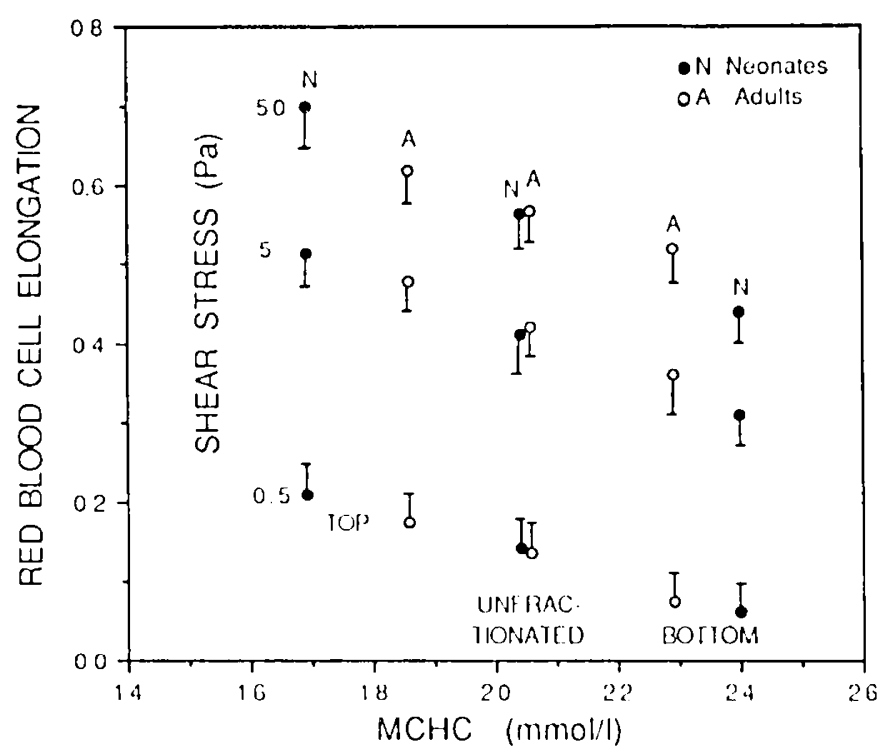

Fig. 3. Elongation (measured in the rheoscope) of top (light), bottom (dense), and unfractionated neonatal $(\bullet)$ and adult $(O)$ RBC plotted as functions of MCHC and shear stress. Data represent mean \pm 1 SD for 10 neonatal and 10 adult samples.

$\mathrm{RBC}$ when the bottom fractions were compared with the top fractions (Table 3 ). Our results indicate that this can be explained by a more pronounced loss of surface area and a greater rise in membrane and $\mathrm{Hb}$ viscosity in the densest neonatal $\mathrm{RBC}$.

We conclude that neonatal $\mathrm{RBC}$ are more fragile than adult $\mathrm{RBC}$, but that the densest neonatal $\mathrm{RBC}$ are neither more fragile nor much older than the average circulating $R B C$ in the neonate. This suggests that the formation of dense RBC cannot be explained by peculiar mechanical properties. The densest neonatal $\mathrm{RBC}$ are extremely rigid due to decreased excess surface area and increased membrane and internal viscosity. Because dense $R B C$ are quickly removed (12), enhanced formation of dense RBC may contribute to the markedly shorter life-span of neonatal $\mathrm{RBC}$ (14).

Acknowledgments. The authors thank Liselotte B. A. Krüger for secretarial assistance and Vivian M. Vargas, M.S.B.A., and John C. Lockhart. Ph.D., for their help in preparing the manuscript.

\section{REFERENCES}

1. Komazawa M, Oski FA 1975 Biochemical characteristics of "young" and "old" erythrocytes of the newhorn infant. J Pediatr 87:102-106

2. Clark MR 1988 Senescence of red blood cells: progress and problems. Physiol Rev 68:503-554

3. Waugh RE, Mohandas N, Jackson CW, Mueller TJ, Suzuki T, Dale GL 1992 Rheologic properties of senescent erythrocytes: loss of surface area and volume with red blood cell age. Blood 79:1351-1358

4. Linderkamp O, Meiselman HJ 1982 Geometric. osmotic, and membrane mechanical properties of density-separated human red cells. Blood 59:11211127

5. Nash GB, Meiselman HI 1983 Red cell and ghost viscoclasticity. Iffects of hemoglobin concentration and in vivo aging. Biophys J 43:63-73

6. Evans E, Mohandas N, Leung A 1984 Static and dynamic rigidities of normal and sickle erythrocytes. J Clin Invest 73:477-488

7. Gahr M, Meves H. Schröter W 1979 Fetal properties in red blood cells of newborn infants. Pediatr Res 13:123!-1236

8. Matovcik LM. Chiu D, Lubin B. Mentzer WC. Lane PA, Mohandas N. Schrier SL 1986 The aging process of human neonatal erythrocytes. Pediatr Res 20:1091-1096

9. Lane PA. Galili U. larocci TA. Shew RA. Mentzer WC 1988 Cellular dehydration and immunoglobulin binding in senescent neonatal erythrocytes. Pediatr Res 23:288-292

10. Linderkamp O. Wu PYK, Meiselman HJ 1982 Deformability of density separated red blood cells in normal newborn infants and adults. Pediatr Res $16: 964-968$

11. Advani R. Mentzer W. Andrews D, Schrier S 1992 Oxidation of hemoglobin $\mathrm{F}$ is associated with the aging process of neonatal red blood cells. Pediatr Res 32:165-168

12. Gattegno L. Bladier D), Cornillot P 1975 Ageing in vivo and neuraminidase treatment of rabbit erythrocytes: influence of half-life as assessed by ${ }^{51} \mathrm{Cr}$ labelling. Hoppe-Seylers Z Physiol Chem 356:39!-397

13. Linderkamp O. Böhler T. Friederichs E. Ludwig H 1993 Age dependency of red blowd cell deformability and density: studies in transient erythroblastopenia of childhood. Br J Haematol 83:125-129

14. Brattehy LE, Garby L, Groth T, Schneider W. Wadman B 1968 Studies on erythro-kinetics in infancy. XII. The mean life span and the life span frequency function of red blood cells formed during foetal life. Acta Paediatr Scand 57:311-320

15. LaCelle PL, Evans EA. Hochmuth RM 1977 Lrythrocyte membrane clasticity, fragmentation, and lysis. Blood Cells 3:335-350

16. Matovcik LM. Mentzer WC 1985 The membrane of human neonatal red cell. Clin Hacmatol 14:203-221

17. Meiselman HJ 1981 Morphological determinants of red cell deformability Scand J Clin Invest 4l(Suppl 156):27-34

18. Weiss T. Ruef P. Linderkamp O 1991 A simplified method to produce micropipettes with flat tips. Clin Hemorheol 11:383-386

19. Bobler T, L.eo A. Stadler A, Linderkamp O 1992 Mechanical fragility of erythrocyte membrane in neonates and adults. Pediatr Res 32:92-96

20. Linderkamp O, Nash GH. Wu PYK, Meiselman HJ 1986 Deformability and intrinsic material properties of neonatal red blood cells. Blood 67:1244-1250

21. Hochmuth RM. Worthy PR. Evans EA 1979 Red cell extensional recovery and the determination of membrane viscosity. Biophys J 26:101-114

22. Evans EA 1973 New membrane concept applied to the analysis of thid shear and micropipette deformed red blood cells. Biophys J 13:941-954

23. Linderkamp O, Wu PYK. Meiselman HJ 1983 Geometry of neonatal and adult red blood cells. Pediatr Res 17:25()-253

24. Cokelet GR, Meiselman IIJ 1968 Rheological comparison of hemoglobin solutions and erythrocyte suspensions. Science 162:275-277

25. Schmid-Schonbein 111976 Blood flow and erythrocyte distribution in the microcirculation. Int Rev Physiol 9:1-62

26. Linderkamp O. Güntner M, Hilll W, Vargas VM 1986 Erythrocyte deformability in the fetus. preterm and term neonate. Pediatr Res 20:93-96

27. Betke K. Marti H, Schlicht I 1959 Estimation of small percentage of feetal hemoglobin. Nature 184:1877-1878

28. Astrup J 1974 Sodium and potassium in human red cells. Variations among centrifuged cells. Scand J Clin Lab Invest 33:231-237

29. Danon Y, Kleimann A, Danon D 1970 The osmotic fragility and density distribution of erythrocytes in the new born. Acta Hacmatol (Basel) $43: 242-$ 247

30. Namboodiri NK, Carter LF, Blalock HM 1975 Applied multivariate analysis and experimental designs. McGraw-Hill, New York, pp 213-238

31. Bard H, Makowski EL Meschia G. Battaglia FC 1970 The relative rates of synthesis of hemoglobins $A$ and $F$ in immature red cells of newborn infants. Pediatrics 45:766-772

32. Bracci R, Martini G. Buonocore G, Talluri B, Berni S, Ottaviani MF, Picchi MP. Casini A 1988 Changes in erythrocyte properties during the first hours of tife: electron spin resonance of reacting sulthydryl groups. Pediatr Res $24: 391-395$

33. Friederichs E. Meiselman HJ 1990) Calcium regulated membrane-attached hemoglobin and mechanical properties of density-fractionated ervithrocyte membranes: implications for hemolytic diseases and RBC aging. Pediatr Res 28:299(abstr) 